\title{
Assessing Mathematical Thinking in Different Type of Primary Schools
}

\author{
Noraini Idris \& Liew Lee Chan \\ Universiti Pendidikan Sultan Idris \\ noridris@upsi.edu.my
}

\begin{abstract}
Mathematical thinking is an act of sense-making and rest on the processes of generalizing, specializing, convincing and conjecturing. The purpose of this study was to determine the level of mathematical thinking students in primary schools and whether there is any difference in the level of mathematical thinking of students from different types of school. The data was collected from 516 Year 4 students which are from 7 primary schools in the state of Terengganu, Johor, Kedah and Federal Territory. Data were collected using a paper-and-pencil test that were directly administered to the sample. The data was analyzed using descriptive and inferential statistics. Statistical software was used to compute the means $(M)$ and corresponding standard deviations $(s d)$. T-tests were also conducted to determine if there are any significant difference in the levels of mathematical thinking of the students according to the different types of schools. The descriptive analysis of the study revealed that primary school students have inadequate level of mathematical thinking $(M=15.25$, $s d=7.19$ ) and only $2.5 \%$ of the students have achieved the adequate level of mathematical thinking based on the "cut off" score of 30.00. The study also found that the level of mathematical thinking of students from Sekolah Kebangsaan $(\mathrm{M}=13.37, \mathrm{sd}=6.85)$ was significantly different than level of mathematical thinking of students from Sekolah Jenis Kebangsaan (Cina) $(M=18.64, \mathrm{sd}=1.63)$ with $t(514)=-7.87, p<.05)$. The analysis further revealed that many students were not able to provide and justified reasoning for their decisions, were not able to make generalization based on the observation of patterns, were not alert that problems can have more than one solution, did not seek for other solutions and were contented with having only one solution.
\end{abstract}

Keywords Mathematical thinking, primary school, type of school, year four students, level of mathematical thinking

\section{BACKGROUND}

In $21^{\text {st }}$ century, many are beginning to understand education not as a process for transmitting knowledge to children, but as a process of opening children's minds to the world around them and to enable children to think for themselves (Healy, 2011; Schank, 2004). After 30 years of research and reform many students still do inefficient rote thinking (Hiebert 2003; Lithner 2008). As a result, improving students' thinking has become one of the main goals of education all over the world. Malaysia also understood it was a need to develop and enhance students' thinking (Malaysian Ministry of Education, 2001; Ministry of Education Malaysia, 2013) in order to actualize the vision of the national education philosophy. Lipman (2003) believes that children need to be assisted to think well and to think for themselves to enable them to become more thoughtful, more judicious, and more reasonable.

Through learning subjects such as mathematics, we expected that students will get chances to develop their thinking. But, based on the common practice in many traditional classrooms today, students are lack of opportunity to apply mathematical thinking in the mathematics classroom. If mathematics teachers only teach students the skills and knowledge by using mathematical procedures in solving routine problems and exercises, it cannot fully develop their students' mathematical thinking. To develop students' mathematical thinking, the 
National Council of Teachers of Mathematics (NCTM) has proposed greater emphasis on the process of problem-solving, reasoning and communication in the mathematics classroom (NCTM, 2000). According to Goos (2004), claimed that mathematical thinking can be generated and tested by students as they participate in equal-status peer partnerships. Thus, students should be allowable to experience the processes through which mathematics develops to encourage mathematical thinking.

In Malaysia, this emphasis on developing mathematical thinking is fairly new and little is known about the extent of the development of students' mathematical thinking. Therefore, this study is aimed at assessing the students' level of mathematical thinking.

\section{Conceptual and Procedural Knowledge in Mathematics}

Conceptual knowledge of mathematics contains of logical relationships constructed internally and existing in the mind as part of a network of ideas. Algorithm is knowledge of the rules and the procedures that one uses in carrying out routine mathematical tasks and also the symbolism that is used to represent mathematics. Step-by-step procedural knowledge exists for routines learned to accomplish some task (John \& Walle, 2001). Computation provides the setting for much procedural knowledge, since algorithms can be acquired through a prescribed, step-bystep sequence of procedures. These procedures can be acquired with understanding or can be applied by memorization.

Reys, Lindquist, Lambdin, Smith, and Suydam (2001) believe that the understanding of this basic mathematical knowledge is a fundamental factor in developing mathematical thinking. This indicated that knowledge of mathematics consists of more than concepts. Furthermore, NCTM (2000) has not only established a process standard that emphasized algorithm proficiency but also on conceptual understanding. Conceptual and procedural knowledge can and should be developed with meaning and understanding (Hiebert,2013; Reys et al.,2001; Rittle-Johnson \& Schneider, 2014). Although the nature of conceptual knowledge requires the establishment of meaningful relationships and connections, it is possible to develop procedural knowledge without regard to meaning. Besides that, it is often said that mathematics teaching should allow pupils to understand mathematical processes rather than simply manipulate algorithms. Many algorithms are 'black box' mysteries to pupils. They are used to generate answers, but often seem disconnected from any logical situations they represent. The algorithm is an elegant end point of a series of sophisticated short cuts, and is closely connected to and representative of the underlying mathematical principles (Lovitt \& Clarke, 1992, p. 135). To inspiring children to think thoroughly, textbooks and achievement tests should not highlight too much on correct written forms.

It is also possible to learn the same algorithm as a series of steps devoid of meaning. Such rote learning has no place in school mathematics, yet it highlights one of the ever-present dangers associated with algorithms. According to Hiebert et al. (1997), students with highly developed rules for manipulating symbols are reluctant to connect these rules to other representations that might give them meaning.

According to Troutman and Lichtenberg (2003), too much stress on procedural knowledge will create pupils who only try to remember facts and follow all rules in the procedure. As a result, it becomes painfully hard for pupils to remember all the rules if they do not know why they are doing the procedure. Therefore, in assessing pupils' mathematical thinking, conceptual and algorithm knowledge that have been taught by their teachers needs to be assessed as well. They play an important role because it was recognized that values existed in each argument and both have provided pupils with a balanced program of understanding mathematics.

\section{Mathematical Reasoning}

One of the vital goals of mathematics is to teach students logical reasoning. Mathematical reasoning and conceptual understanding cannot be separated from content; they are intrinsic to the mathematical discipline that students master at more advanced levels (CDSMC, 2006; English, 2013). Reasoning has many definitions; all emphasize thinking of mathematics in 
nature (Kennedy \& Tipps, 2000). According to Lithner (2015), reasoning is defined as the line of thought that is adopted to produce assertions and reach conclusions when solving tasks. It seems that reasoning activity and mathematical thinking are closely linked, hence mathematics teachers should let pupils to practice reasoning in the classroom. The purpose is to provide chance for pupils to develop their thinking skills. Pupils will be able to determine what is true and aware of the processes that have been done in getting better understanding of how the $y$ are learning mathematics by doing reasoning (Sonnabend, 1997).

Similar phenomena are happening in the Malaysian mathematics classroom. Mathematics lesson is carried out by referring to the mathematics syllabus, mathematics specification, as well as text book. These resources are planned such a way in helping and guiding teachers to plan and deliver mathematics knowledge to primary children systematically, but less emphasis on children's mathematical thinking and reasoning. With the traditional stereotype practice creates suspicious among public whether students are able to think mathematically in the certain topics they have gone through. On top of that, developing mathematical language, selecting and using materials, and developing reasoning, should be integrated with the other areas of mathematics.

\section{Mathematics Instructional Materials}

In Malaysia primary education, pupils are encouraged to be actively involved in the teaching and learning processes in acquiring mathematical skills and knowledge. Teachers should plan their instructional activities properly in order to allow students to engage actively in the mathematics classroom. Most of these instructional materials are planned and provided by Ministry of Education Malaysia to schools with systematically develop by experience mathematics educators. Among the most popular teaching and learning resources for mathematics teacher are textbooks. There are different textbooks are used in each level of primary study. Every government schools will only use recognize textbooks which have approved by Textbooks Department of Malaysia. The contents of textbooks are based totally on the syllabus with focusing on lots of mathematical explanations in the form of diagrams, pictures, symbols, including definitions, and exercises. Most of the textbook contents are also in terms of behaviourist-based with emphasizing on the mastery of procedural knowledge of mathematics.

According to the NCTM (1989), teaching and learning activities should be focused on the usage of instructional materials that involve using manipulative materials, discussion in cooperative groups, writing about mathematics and justifying thinking in solving problems. The teaching and learning activities are aimed at improving children's mathematical thinking in the mathematics classroom (Hatfield, Edwards, Bitter, \& Morrow, 2000) besides motivate them in studying mathematics meaningfully (Turner, Warzon \& Christensen, 2011). The differences between the Malaysian and NCTM curriculum might have its own impact on the students' mathematical thinking respectively.

\section{Problem Solving}

Problem solving is a skill that is considered to be important. It is a skill that could be used throughout the course of one's life not only in academics but even in getting a job position (Magno, 2011). Problem solving and mathematical thinking is synonymous. Engaging pupils in problem solving activity will develop their mathematical thinking (Cathcart, Pothier, Vance, and Bezuk, 2000). In the mathematics context, a problem solving is a planned process that needs to be carried out in order to obtain a certain solution of a problem that might not be achieved immediately (Nor Shah \& Sazelli, 2010). It is a challenge that comes into our environment and forces us to search for solution strategies. When pupils devise a strategy for problem solving, they use their thinking to process the information given, characterize it, and come up with a solution (Troutman \& Lichtenberg, 2003). Practically, one would conclude that the traditional story problems found at the end of textbook chapters do not qualify as bona fide problems. Generally, there is no evidence that pupils want to work at this type of problem. Usually, they quickly glance at the problem to note word clues, then immediately apply some operation to the data 
to arrive at an answer. It was noted that this type of problem hardly serves to develop one's mathematical thinking (Cathcart et al., 2000). In fact, pupils must be presented with some interesting and challenging problems so that they will gain experience in analyzing information and provide reasons for their solutions.

According to Troutman and Lichtenberg (2003), the effective way in enhancing pupils' mathematical thinking is teaching mathematics through problem solving with reasoning. Mathematics should not be taught in isolation as what is happening in our classrooms today. In fact, the process standards are met when pupils encounter intriguing mathematical problems, reason and offer evidence for their thinking (Kennedy \& Tipps, 2000). In the Malaysian mathematics primary education, pupils were prepared so that they will be able to solve mathematical problems at the end of each topic without much focus on expressing reasons for their solutions. Most of the questions emphasize on the applications of algorithms in solving mathematics problems.

\section{Mathematical Communication}

Effective teaching of mathematics rests heavily on considerations about how children learn. The content of mathematical communication can be treated as an artifact of reflection, refinement, discussion, and modification (Yang, Chang, Cheng \& Chan, 2016). This learning style is so comprehensive because students will have opportunity to explain, talk about mathematics, make conjectures and defend their thinking orally as well as in writing stimulate deeper understanding because talking and writing about mathematics are essential parts of learning mathematics. In a mathematics classroom, there are varieties of language usage ranging from informal to formal teacher or student presentations (Chronaki \& Christiansen, 2005). Informal talk refers to the interaction between mathematics subject and students, and between teacher and students; it is important at all key stages in developing understanding. However, formal styles may be used by students to express their understanding either in spoken or written form. To ensure students acquire understanding, they need to be able to listen, talk, read and write effectively in both informal and formal styles.

In the mathematics classroom, communication means sharing of mathematical understanding and it is ultimately based on understanding and utilizing the symbols, language and rituals of the school mathematics register. In fact, Noraini Idris (2006) expressed that mathematics language is viewed as a medium through which mathematics content is communicated. Mathematics is one of the languages in the communication system. Yet, more than any other discipline, mathematics requires careful translation, much as any foreign language does. Hence, teachers should encourage students to communicate in the mathematics classroom because it will develop students' cognitive understanding of the topics they have learned.

\section{PURPOSE AND SIGNIFICANCE OF THE STUDY}

The purpose of the study was to know the level of student's mathematical thinking. By using the Test on Students' Mathematical Thinking Malaysia, the study will be able to find the level of the students' mathematical thinking in primary school. The significance of the study was as below:

i) To share the findings and will contribute towards further improvement in the effort to develop students' mathematical thinking from different type of school.

ii) To determine the level of students' mathematical thinking from different type of school which will help in planning programs.

\section{METHODOLOGY}

This study used a quantitative approach to assess the Year 4 pupils' level of mathematical thinking. A cross-sectional survey design with direct administration of paper-and-pencil test 
items was used to describe the variable in this study. Since it has been well established that the best method to describe the existing characteristics of a large group of person is the survey method (Chua, 2012; Ismail, 2016). Therefore, this study is conducted to study the mathematical thinking of primary school pupils. It has been well established that the best method to describe the existing characteristics of a large group of persons is the survey method. Cross-sectional survey was used in the study because the data was collected at just one point in time from a sample that had been drawn from a predetermined population in order to describe the existing characteristics at that point of time. The best way to collect data for the cross-sectional survey in this study was the direct administration of the paper-and-pencil test items.

\section{Sample}

The participants of this study consisted of 516 Year Four primary school pupils in Malaysia. The sample used in this research were selected from 7 schools, where two school each were selected from Terengganu, Kedah and Johor and one school from Kuala Lumpur. Samples were chosen from all students in the two classes of Year Four pupils of each school. Even though the sample was not selected randomly from the population, the Year Four students from the selected schools are representative of Year Four Students in Malaysia. The study has observed certain criteria such as ethnicity, diversity in student population, locality, and types of schools, in determining the selected school.

\section{Instrumentation}

In this study, the instrument for data collection consisted of a paper-and-pencil test of 9 items. All the items in the test are of limited response. Table 1 presents the mathematical thinking components and mathematical content that are assessed in the instrument.

Table 1 Mathematical Thinking Components and Mathematical Content Measured by Each Item

\begin{tabular}{|c|c|c|}
\hline Item & Mathematical Thinking Component & Mathematical Content \\
\hline 1 & Decision making Justifying decision & Whole Numbers Operation \\
\hline 2 & Decision making Justifying decision & Time Measurement \\
\hline 3 & Problem Solving & Division of whole numbers \\
\hline 4 & Decision making Justifying decision & Time Measurement \\
\hline 5 & $\begin{array}{l}\text { Decision making Justifying Decision } \\
\text { Proportional reasoning }\end{array}$ & Time, Proportion \\
\hline 6 & Spatial reasoning & Solid Geometry \\
\hline 7 & Conceptual understanding & Fraction \\
\hline 8 & Conceptual understanding & Fraction \\
\hline 9 & Conjecturing, generalization & Patterns \\
\hline
\end{tabular}

A pilot study was conducted to ascertain the reliability of the test. The pilot study revealed the test to be reliable with a Cronbach alpha value of 0.76 .

\section{Data Analysis}

The data collected using The Mathematical Thinking Test were analyzed using descriptive and inferential statistics. Frequency, percentages, means and corresponding standard deviations were computed using the statistical software. $t$-tests were also conducted to determine if there 
are any significant difference in the levels of mathematical thinking of the students.

\section{RESULT}

\section{Analysis of the Overall Scores of the Mathematical Thinking Test}

Table 2 shows the frequencies and percentages of the overall scores obtained by the students in the Mathematical Thinking Test. The mean and standard deviation of the overall scores of the Mathematical Thinking Test and the frequencies and percentages of the scores of the test are presented. The descriptive analysis of the overall scores of the Mathematical Thinking Test revealed that the mean was 15.25 and the standard deviation was 7.19. The lowest score obtained was 0 and the highest score obtained was 41 . The maximum possible score in this test was 60 .

Table 2 Frequencies and Percentages of the Overall Score of the Mathematical Thinking Test

\begin{tabular}{lll}
\hline Score & Frequency & Percentage \\
\hline $0-5$ & 37 & 7.2 \\
$6-10$ & 99 & 19.2 \\
$11-15$ & 160 & 31.0 \\
$16-20$ & 104 & 20.2 \\
$21-25$ & 73 & 14.1 \\
$26-30$ & 30 & 5.8 \\
$31-35$ & 9 & 1.7 \\
$36-40$ & 3 & 0.6 \\
$41-45$ & 1 & 0.2 \\
$46-50$ & 0 & 0 \\
$51-55$ & 0 & 0 \\
$56-60$ & 0 & 100.0 \\
\hline Total & 516 & \\
\hline
\end{tabular}

Based on Table 2, the range of scores with the highest percentage $(31.0 \%)$ was the score between 11 and 15 . About $19.2 \%$ of the pupils obtained a score between 6 and 10 . About $7.2 \%$ of the pupils obtained the lowest range of scores which was between 0 and 5. Only $2.5 \%$ of the pupils obtained scores higher than half of the total possible scores of 60 . No students obtained scores from 46 to 60 . 


\section{Analysis of scores for each item of the Mathematical Thinking Test}

The means and standard deviation of the scores of each of the nine items in the Mathematics Thinking Test are presented. The frequencies and percentages of the types of response for each item are also presented.

\section{Analysis for Item 1 of the Mathematical Thinking Test}

Descriptive analysis of score for Item 1 revealed mean score of 1.87 with a standard deviation of 1.62 .

Table 3 Frequencies and Percentages of the Responses of Students for Item 1 of the Mathematical Thinking Test

Types of response

Omitted

Incorrect answer (without explanation)

Correct answer (without explanation)

Incorrect answer

(with reasonable explanation)

Correct answer (unreasonable explanation)

Correct answer (reasonable explanation)

$\begin{array}{ccc}\text { Score } & \text { Frequency } & \text { Percentage } \\ 0 & 99 & 19.2 \\ 1 & 205 & 39.7 \\ 2 & 31 & 6.0 \\ 3 & 84 & 16.3 \\ & & \\ 4 & 40 & 7.8 \\ 5 & 57 & 11.0 \\ & 516 & 100.0\end{array}$

Table 3 shows that about slightly more than half (58.9\%) of the pupils either did not respond or gave incorrect answer without explanation to Item 1. Only $11.0 \%$ of the students gave correct answers with reasonable explanation in Item 1.

\section{Analysis for Item 2 of the Mathematical Thinking Test}

For Item 2, descriptive analysis showed mean score of 2.61 with a standard deviation of 1.89 .

Table 4 Frequencies and Percentages of the Responses of Students for Item 2 of the Mathematical Thinking Test

\begin{tabular}{lccc}
\hline Types of response & Score & Frequency & Percentage \\
\hline Omitted & 0 & 93 & 18.0 \\
Incorrect answer (without explanation) & 1 & 105 & 20.3 \\
Correct answer (without explanation) & 2 & 52 & 10.1 \\
Incorrect answer & 3 & 56 & 10.9 \\
(with reasonable explanation) & & & \\
Correct answer (unreasonable explanation) & 4 & 79 & 15.3 \\
Correct answer (reasonable explanation) & 5 & 131 & 25.4 \\
\hline
\end{tabular}

Table 4 shows that almost one quarter of the students (25.4\%) gave correct answers with reasonable explanation in Item 2.

\section{Analysis for Item 3 of the Mathematical Thinking Test}

For Item 3, the result of the descriptive analysis showed a mean score of 1.43 and a standard deviation of 1.57. The lowest score obtained for Item 3 was 0 and the highest was 11 . The maximum possible score for this item was 11 .

Table 5 Frequencies and Percentages of the Responses of Students for Item 3 of the Mathematical Thinking Test

\begin{tabular}{lccc}
\hline Types of response & Score & Frequency & Percentage \\
\hline Item 3a & & & \\
\hline Omitted/Incorrect & 0 & 239 & 46.3 \\
\hline
\end{tabular}




\begin{tabular}{llll}
\hline Correct & 1 & 277 & 53.7 \\
\hline More than one answer & 2 & 0 & 0 \\
\hline & & 516 & 100.0 \\
\hline Item 3b & 0 & 270 & 52.3 \\
\hline Omitted/ Incorrect Explanation & 1 & 208 & 40.3 \\
\hline Partial explanation & 2 & 38 & 7.4 \\
\hline Full explanation & & 516 & 100.0 \\
\hline Item 3c & & \\
\hline Omitted/Incorrect & 0 & 440 & 85.3 \\
\hline Correct answer (without explanation) & 1 & 64 & 12.4 \\
\hline Correct answer (reasonable explanation) & 2 & 12 & 2.3 \\
\hline & & 516 & 100.0 \\
\hline Item 3d & & & 99.2 \\
\hline Omitted/Incorrect & 0 & 512 & 0.8 \\
\hline Correct & 1 & 4 & 100.0 \\
\hline Item 3e & & 516 & 92.4 \\
\hline Omitted/ incorrect & & & 3.9 \\
\hline Incoherent explanation & 0 & 477 & 3.5 \\
\hline Partial listing of possible answers & 1 & 20 & 0.2 \\
\hline Full listing of possible answers & 2 & 18 & 0 \\
\hline Explain using logical reasoning & 3 & 1 & 100.0 \\
\hline & 4 & 0 & 516 \\
\hline
\end{tabular}

Table 5 shows that for part (a) of Item 3, about half $(53.7 \%)$ of pupils answered correctly. For part (b) of Item 3, 40.3\% of the pupils gave partial explanation and $7.4 \%$ of them gave full explanation. For part (c) of Item 3, only $2.3 \%$ were able to give correct answers with reasonable explanation. For part $(\mathrm{d})$ of Item 3 , only $0.2 \%$ of the students were able to give a full listing of all the possible answers.

\section{Analysis for Item 4 of the Mathematical Thinking Test}

For Item 4, the result of the descriptive analysis showed a mean score of 1.84 and a standard deviation of 1.83 .

Table 6 Frequencies and Percentages of the Responses of Students for Item 4 of the Mathematical Thinking Test

\begin{tabular}{lccc}
\hline Types of response & Score & Frequency & Percentage \\
\hline Omitted & 0 & 158 & 30.6 \\
\hline Incorrect answer (without explanation) & 1 & 145 & 28.1 \\
\hline Correct answer (without explanation) & 2 & 43 & 8.3 \\
\hline $\begin{array}{l}\text { Incorrect answer } \\
\text { (with reasonable explanation) }\end{array}$ & 3 & 47 & 9.1 \\
\hline Correct answer (unreasonable explanation) & 4 & 38 & 7.4 \\
\hline Correct answer (reasonable explanation) & 5 & 85 & 16.5 \\
\hline
\end{tabular}

Table 6 shows that $58.7 \%$ of the pupils either did not respond or gave the incorrect answer without explanation to item 4. About $16.5 \%$ gave correct answers with reasonable explanation in Item 4.

\section{Analysis for Item 5 of the Mathematical Thinking Test}

For Item 5, the result of the descriptive analysis showed a mean score of 0.98 and a standard deviation of 1.28 . 
Table 7 Frequencies and Percentages of the Responses of Students for Item 5 of the Mathematical Thinking Test

\begin{tabular}{lccc}
\hline Types of response & Score & Frequency & Percentage \\
\hline Omitted & 0 & 257 & 49.8 \\
\hline Incorrect answer (without explanation) & 1 & 142 & 27.5 \\
\hline Correct answer (without explanation) & 2 & 25 & 4.8 \\
\hline $\begin{array}{l}\text { Incorrect answer } \\
\text { (with reasonable explanation) }\end{array}$ & 3 & 60 & 11.6 \\
\hline Correct answer (unreasonable explanation) & 4 & 27 & 5.2 \\
\hline Correct answer (reasonable explanation) & 5 & 5 & 1.0 \\
\hline
\end{tabular}

Table 7 shows that $77.3 \%$ of the pupils either did not respond or gave the incorrect answer without explanation to item 5 . Only $1.0 \%$ gave correct answers with reasonable explanation in Item 5.

\section{Analysis for Item 6 of the Mathematical Thinking Test}

For Item 6, the result of the descriptive analysis showed a mean score of 0.16 and a standard deviation of 0.39 . The lowest score obtained for Item 6 was 0 and the highest score obtained was 2 . The maximum possible score for this item was 2 .

Table 8 Frequencies and Percentages of the Responses of Students for Item 6 of the Mathematical Thinking Test

\begin{tabular}{llll}
\hline Types of response & Score & Frequency & Percentage \\
\hline Item 6a & & & \\
\hline Omitted/Incorrect & 0 & 478 & 92.6 \\
\hline Correct & 1 & 38 & 7.4 \\
\hline & & 516 & 100.0 \\
\hline Item 6b & & & \\
\hline Omitted/Incorrect & 0 & 468 & 90.7 \\
\hline Correct & 1 & 48 & 9.3 \\
\hline & & 516 & 100.0 \\
\hline
\end{tabular}

Table 8 shows that for part (a) of Item 6 , only $7.4 \%$ gave correct answer to the question. For part (b) of Item 6, only 9.3\% gave correct answer to the question. About $16.5 \%$ gave correct answers with reasonable explanation in Item 6.

\section{Analysis for Item 7 of the Mathematical Thinking Test}

For Item 7, the result of the descriptive analysis showed a mean score of 0.74 and a standard deviation of 0.74 . The lowest score obtained for Item 7 was 0 and the highest score obtained was 4 . The maximum possible score for this item was 4 .

Table 9 Frequencies and Percentages of the Responses of Students for Item 7 of the Mathematical Thinking Test

\begin{tabular}{llll}
\hline Types of response & Score & Frequency & Percentage \\
\hline Item $7 \mathrm{i}$ & & & \\
\hline Omitted/Incorrect & 0 & 238 & 46.1 \\
\hline Correct & 1 & 278 & 53.8 \\
\hline & & 516 & 100.0 \\
\hline Item 7ii & & & \\
\hline Omitted/Incorrect & 0 & 419 & 81.2 \\
\hline One answer correct & 1 & 92 & 17.8 \\
\hline
\end{tabular}




\begin{tabular}{llll}
\hline Two answers correct & 2 & 4 & 0.8 \\
\hline More than 2 answers correct & 3 & 1 & 0.2 \\
\hline & & 516 & 100.0 \\
\hline
\end{tabular}

Table 9 shows that for part (i) of Item 7, 53.9\% gave correct answer to the question. For part (ii) of Item 7, about $81.2 \%$ of the students either did not respond or gave incorrect answer and only $18.8 \%$ gave correct answer or answers to the question. Only one student gave more than 2 correct answers.

\section{Analysis for Item 8 of the Mathematical Thinking Test}

For Item 8, the result of the descriptive analysis showed a mean score of 0.85 and a standard deviation of 0.79 . The lowest score obtained for Item 8 was 0 and the highest score obtained was 5. The maximum possible score for this item was 5 .

Table 10 Frequencies and Percentages of the Responses of Students for Item 8 of the Mathematical Thinking Test

\begin{tabular}{llll}
\hline Types of response & Score & Frequency & Percentage \\
\hline Item $8 \mathrm{i}$ & & & \\
\hline Omitted/Incorrect & 0 & 184 & 35.7 \\
\hline Correct & 1 & 332 & 64.3 \\
\hline & & 516 & 100.0 \\
\hline Item 8ii & 0 & 449 & 87.0 \\
\hline Omitted/Incorrect & 1 & 67 & 13.0 \\
\hline Correct & & 516 & 100.0 \\
\hline & & & \\
\hline Item 8iii & 0 & 487 & 94.4 \\
\hline Omitted/Incorrect & 1 & 23 & 4.5 \\
\hline One answer correct & 2 & 4 & 0.8 \\
\hline Two answers correct & 3 & 2 & 0.4 \\
\hline More than 2 answers correct & & 516 & 100.0 \\
\hline
\end{tabular}

Table 10 shows that for part (i) of Item 8, 64.3\% were able to answer the question correctly. For part (ii) of Item 8, about $87.0 \%$ of the students either did not respond or gave incorrect answer and only $13.0 \%$ were able to answer the question correctly. For part (iii) of Item 8 , about $94.4 \%$ either did not answer or give the wrong answer. Only $4.5 \%$ of the pupils were able to give one correct answer and only $1.2 \%$ were able to give two or more correct answers.

\section{Analysis for Item 9 of the Mathematical Thinking Test}

For Item 9, the result of the descriptive analysis showed a mean score of 4.76 and a standard deviation of 2.99 .

Table 11 Frequencies and Percentages of the Responses of Students for Item 9 of the Mathematical Thinking Test

\begin{tabular}{llll}
\hline Types of response & Score & Frequency & Percentage \\
\hline Item 9a & & & \\
\hline Omitted/Incorrect & 0 & 62 & 12.0 \\
\hline Correct & 1 & 454 & 88.0 \\
\hline & & 516 & 100.0 \\
\hline Item 9b & & & 14.5 \\
\hline Omitted/Incorrect & 0 & 75 & 85.5 \\
\hline Correct & 1 & 441 & \\
\hline
\end{tabular}




\begin{tabular}{|c|c|c|c|}
\hline & & 516 & 100.0 \\
\hline \multicolumn{4}{|l|}{ Item 9c } \\
\hline Omitted/Incorrect & 0 & 71 & 13.8 \\
\hline \multirow{2}{*}{ Correct } & 1 & 445 & 86.2 \\
\hline & & 516 & 100.0 \\
\hline \multicolumn{4}{|l|}{ Item 9d } \\
\hline Omitted/Incorrect & 0 & 87 & 16.9 \\
\hline \multirow[t]{2}{*}{ Correct } & 1 & 429 & 83.1 \\
\hline & & 516 & 100.0 \\
\hline \multicolumn{4}{|l|}{ Item $9 \mathrm{e}$} \\
\hline Omitted/Incorrect & 0 & 323 & 62.6 \\
\hline Correct without explanation & 1 & 108 & 20.9 \\
\hline Correct with partial explanation & 2 & 37 & 7.2 \\
\hline \multirow[t]{2}{*}{ Correct with full explanation } & 3 & 48 & 9.3 \\
\hline & & 516 & 100.0 \\
\hline \multicolumn{4}{|l|}{ Item 9f } \\
\hline Omitted/Incorrect & 0 & 401 & 77.7 \\
\hline Correct without explanation & 1 & 52 & 10.1 \\
\hline Correct with partial explanation & 2 & 22 & 4.3 \\
\hline \multirow[t]{2}{*}{ Correct with full explanation } & 3 & 41 & 8.0 \\
\hline & & 516 & 100.0 \\
\hline \multicolumn{4}{|l|}{ Item $9 \mathrm{~g}$} \\
\hline Omitted/Incorrect & 0 & 478 & 92.6 \\
\hline Correct without explanation & 1 & 14 & 2.7 \\
\hline Correct with partial explanation & 2 & 7 & 1.4 \\
\hline \multirow[t]{2}{*}{ Correct with logical reasoning } & 4 & 17 & 3.3 \\
\hline & & 516 & 100.0 \\
\hline \multicolumn{4}{|l|}{ Item 9h } \\
\hline Omitted/Incorrect & 0 & 508 & 98.4 \\
\hline Correct without explanation & 1 & 1 & 0.2 \\
\hline Correct with partial explanation & 2 & 0 & 0 \\
\hline \multirow[t]{2}{*}{ Correct with logical reasoning } & 4 & 7 & 1.4 \\
\hline & & 516 & 100.0 \\
\hline
\end{tabular}

Table 11 shows that part (a), (b), (c), and (d) of Item 9, some 88.0\%, 85.5\%, 86.2\%, and 83.1\% of the students were able to answer correctly the questions respectively. For part (e) and (f) of Item 9 , only $9.3 \%$ and $8.0 \%$ of the sample answered correctly with full explanation respectively. For part $(\mathrm{g})$ of Item $9,3.3 \%$ of the pupils were able to answer correctly using logical reasoning. For part (h) of Item 9, only $1.6 \%$ of the students were able to answer correctly where $1.4 \%$ answer using logical reasoning.

\section{Comparison of the score of students from Sekolah Kebangsaan (SK) and Sekolah Jenis Kebangsaan Cina (SJKC) in Mathematic Thinking Test}

Table 12 describes the results obtained from the $t$-test conducted on the overall score of students from Sekolah Kebangsaan and Sekolah Jenis Kebangsaan (Cina) in the Mathematical Thinking Test and the $t$-tests conducted on the scores of these students for every item in the test. The result of the $t$-test shows that the overall score in the Mathematical Thinking Test of students from Sekolah Kebangsaan $(M=13.37, s d=6.85)$ was significantly different than the score in the overall mathematical thinking test of students from Sekolah Jenis Kebangsaan (Cina) $(M=18.64, s d=7.63)$ with $t(514)=-7.8, p<0.05)$. 
Table 12 Results of $t$-Test on the Scores of Each Item in the Mathematical Thinking Test of Students from Sekolah Kebangsaan and Sekolah Jenis Kebangsaan (Cina).

\begin{tabular}{|c|c|c|c|c|c|}
\hline \multirow[t]{2}{*}{ Item } & \multicolumn{2}{|c|}{$\begin{array}{c}\text { Sekolah Kebangsaan } \\
n=324\end{array}$} & \multicolumn{2}{|c|}{$\begin{array}{l}\text { Sekolah Jenis Kebangsaan } \\
\text { (Cina) } \\
\quad n=192\end{array}$} & \multirow[t]{2}{*}{$t$} \\
\hline & $M$ & $S D$ & $M$ & $S D$ & \\
\hline 1 & 1.55 & 1.50 & 2.41 & 1.67 & $-5.85^{*}$ \\
\hline 2 & 2.06 & 1.87 & 3.54 & 1.52 & $-9.73 *$ \\
\hline 3 & 1.15 & 1.49 & 2.16 & 3.81 & $-3.53 *$ \\
\hline 4 & 1.79 & 1.92 & 1.92 & 1.68 & -0.82 \\
\hline 5 & 0.98 & 1.28 & 0.98 & 1.28 & -0.08 \\
\hline 6 & 0.16 & 0.38 & 0.18 & 0.41 & -0.46 \\
\hline 7 & 0.69 & 0.71 & 0,81 & 0.78 & -1.72 \\
\hline 8 & 0.69 & 0.77 & 1.10 & 0.77 & $-5.92 *$ \\
\hline 9 & 4.30 & 2.65 & 5.54 & 3.36 & $-4.37 *$ \\
\hline
\end{tabular}

$*$ significant at $p<0.05$

Table 12 revealed that the difference between the scores of students from Sekolah Kebangsaan and Sekolah Jenis kebangsaan (Cina) were significant at $p<0.05$ for Item 1, Item 2, Item 3, Item 8 and Item 9. For Item 1, the score of students from Sekolah Kebangsaan $(M=1.55$, $s d=1.50)$ was significantly different than the score of students from Sekolah Jenis Kebangsaan (Cina) $(M=2.41, s d=1.67)$. For Item 2 , the score of students from Sekolah Kebangsaan $(M=$ 2.06, $s d=1.87$ ) was significantly different than the score of students from Sekolah Jenis Kebangsaan (Cina) $(M=3.54, s d=1.52)$. For Item 3, the score of pupils from Sekolah Kebangsaan $(M=1.15, s d=1.49)$ was significantly different than the score of students from Sekolah Jenis Kebangsaan (Cina) $(M=2.16, s d=3.81)$. For Item 8 , the score of students from Sekolah Kebangsaan $(M=0.69, s d=0.77)$ was significantly different than the score of students from Sekolah Jenis Kebangsaan (Cina) $(M=1.10, s d=0.77)$. For Item 9, the score of pupils from Sekolah Kebangsaan $(M=4.30, s d=2.65)$ was significantly different than the score of students from Sekolah Jenis Kebangsaan (Cina) $(M=5.54, s d=3.36)$.

\section{DISCUSSION}

\section{Level of Mathematical Thinking of Primary School Pupils in Malaysia}

In interpreting the results, an arbitrary numerical "cut-off" score of 30.0 in the Mathematical Thinking Test defines the adequacy level of mathematical thinking. A mean score of more than 30.0 indicates that the primary school pupils have adequate level of mathematical thinking. Meanwhile, a mean score less than the "cut-off' points of 30.0 indicates that the primary school pupils have inadequate level of mathematical thinking. The results show that, as a whole, the primary school pupils in Malaysia have inadequate level of mathematical thinking. The results further show that only $2.5 \%$ of the pupils have achieved the adequate level of mathematical thinking.

Findings of the study also revealed that the primary school pupils also were unable to show their mathematical thinking in all the nine items of the test. The mean scores of all the nine items were all lower than the "cut-off points of the items. Further analysis of every item of the test revealed that a large majority of the pupils were unable to provide reasoning for their decisions.

The ability to explain any decision using reasonable explanation is very important. CDSMC (2006) believed that pupils should be able to justify their solutions, starting with informal mathematical reasoning and advancing to more formal mathematical proofs from their earliest years. The results of analysis, of Item 1, Item 2 and Item 4 indicated that many pupils 
were unable to justify and provide reasoning for their decisions. For Item 1, even though about $40 \%$ of the pupils gave the correct response, only $11 \%$ gave reasonable explanation for their response. For Item 2, only $25 \%$ of the pupils were able to give reasonable explanation for their decision while for Item 4 , about $16.5 \%$ of the pupils provided reasonable explanations for their decisions.

Another aspect of mathematical thinking is to ascertain the possibilities of other solutions to a problem. This aspect was not found in most pupils as was revealed upon analysis of Item 3. In Item 3, pupils were provided a problem situation that has more than one solution. The results for analysis of this item indicate that many pupils were not alert that the problem can have more than one solution. Most pupils did not seek other solutions and were contented with having only one solution. Those few who knew that more than one solution existed did not know how to identify all the possible solutions.

According to CDSMC (2006), mathematics makes sense to pupils who have a conceptual understanding of the concepts that are taught to them. Analysis of Item 7 and Item 8 revealed that many pupils had not understood the concept of fraction. These pupils were not able to develop meaningful understanding of the idea of fraction as they were not able to connect to the idea of the "whole" involved in fraction. According to CDSMC (2006), pupils without conceptual understanding might not know how to apply skills, when to apply them and why. These pupils who lack understanding of the structure and logic of mathematics will not be able to use concepts effectively, flexibly and appropriately. They are unable to see the big picture and cannot apply their knowledge to new situations and do not readily recognize their procedural errors.

Further analysis of Item 7 and Item 8 also revealed that most pupils were not aware of the possibility of other representation of fractions. Mathematical representation is one of the important components of mathematical thinking. Analysis of Item 7 and Item 8 indicate that most primary school pupils do not know that a concept like fraction has many ways of representation. CDSMC (2006) claimed that pupils should also be able to classify relevant mathematical generalizations from observing patterns. The results of analysis of Item 9 shows that most primary school pupils in Malaysia were unable to make generalization based on the observation of patterns.

\section{Differences in the Level of Mathematical Thinking of Primary School Pupils in Malaysia}

The level of mathematical thinking of pupils depends on the type of school the pupils attend. The result of the $t$-test revealed that the level of mathematical thinking of pupils from Sekolah Kebangsaan $(M=13.37, s d=6.85)$ was different than the level of mathematical thinking of pupils from Sekolah Jenis Kebangsaan (Cina) $(M=18.64, s d=7.63)$. The study found that the ability to provide reasoning on decision making about time by pupils from Sekolah Kebangsaan $(M=2.06, s d=1.87)$ was different from that of pupils from Sekolah Jenis Kebangsaan (Cina) $(M=3.54, s d=1.52)$. This result indicates that the type of school the pupils go to can be a factor affecting the ability of pupils to provide reasoning on decision making about time.

The study also found that the tendency to provide multiple representations of concepts like fractions by pupils from Sekolah Kebangsaan $(M=0.69$, $s d=0.77)$ was significantly different from that of pupils from Sekolah Jenis Kebangsaan (Cina) $(M=1.10, s d=0.77)$. This can be interpreted as pupils' tendency to provide multiple representations of concepts may depend on factors such as the type of school they go to. Moreover, the pupils from different types of school differ in their tendency to seek alternative solutions to a problem. The findings also show that the tendency to seek alternative solutions to a problem by pupils from Sekolah Kebangsaan $(M=1.15, s d=1.49)$ was different from that of pupils from Sekolah Jenis Kebangsaan (Cina) $(M=2.16, s d=3.81)$. Besides that, the ability to make generalizations from patterns may depend on the type of school the pupils come from as the results of the study also discovered that pupils from Sekolah Kebangsaan $(M=4.30, s d=2.65)$ have different capability 
in making generalizations from patterns as compared to pupils from Sekolah Jenis Kebangsaan (Cina) $(M=5.54, s d=3.36)$.

\section{CONCLUSION}

Mathematics is not only the science and language of patterns, but also an art and a way of thinking. Learning with broad perspective is important because it will help students to think and connect mathematical ideas in different environments and situation. This exposure will lead students' thinking across the boundary of mathematics and make their justifications more concrete. Teacher educators at the faculties of education and teacher education institutes should include in their course curriculum the need to increase student teachers' consciousness about the current students' level of mathematical thinking. Teacher education programs should place greater emphasis on the assessment and development of students' mathematical thinking. Student teachers should be exposed to the approaches of developing student's ability to reason in their mathematics teaching. In this study, the findings show that students' mathematics thinking and reasoning ability are low, therefore there is a need for teacher education programs to bring theory into practice by emphasizing thinking elements in their training session. On top of that, simulations, demonstrations and expositions should be conducted in real and practical way to ensure every trainee is able to absorb the knowledge that can be translated with success into classroom practice.

\section{REFERENCES}

Cathcart, W. G., Pothier, Y. M., Vance, J. H., \& Bezuk, N. S. (2000). Learning Mathematics in Elementary and Middle Schools. New Jersey: Merrill.

Chronaki, A., \& Christiansen, I. M. (2005). Challenging perspectives on Mathematics classroom communication: From representations to contexts, interactions, and politics. Challenging Perspectives on Mathematics Classroom Communication (pp. 6-8). Connecticut: Information Age.

Chua, Y. P. (2012). Mastering research methods. Mcgraw-Hill Education.

Curriculum Development and Supplemental Materials Commission [CDSMC] (2006). Mathematics framework for California public schools: Kindergarten through grade twelve. Sacramento, CA: California Department of Education.

English, L. D. (Ed.). (2013). Mathematical reasoning: Analogies, metaphors, and images. Routledge.

Goos, M. (2004). Learning mathematics in a classroom community of inquiry. Journal for Research in Mathematics Education, 35(4), 258-291.

Hatfield, M. M., Edwards, N. T., Bitter, G. G., \& Morrow, J. (2000). Mathematical methods for elementary and middle school teachers (4th ed.). New York: Wiley.

Healy, J. M. (2011). Endangered Minds: Why Children Dont Think And What We Can Do About I. Simon and Schuster.

Hiebert, J., \& Carpenter, T. P. (1992). Learning and teaching with understanding. In D. A. Grouws (Ed.), Handbook of research on mathematics teaching and learning: A project of the National Council of Teachers of Mathematics (pp. 65-97). New York: Macmillan

Hiebert, J., Carpenter, T., Fuson, K, Murray, A., Oliver, P. H,, \& Wearne, D. (1997). Designing classrooms for learning mathematics with understanding. Porthsmouth, NH: Heinemann.

Hiebert, J. (2003). What research says about the NCTM standards. In J. Kilpatrick, G. Martin, \& D. Schifter (Eds.), A research companion to principles and standards for school mathematics (pp. 5-26). Reston, Va.: National Council of Teachers of Mathematics.

Hiebert, J. (2013). Conceptual and procedural knowledge: The case of mathematics. Routledge.

Ismail, R. (2016). Metodologi penyelidikan: teori dan praktis. Penerbit Universiti Kebangsaan Malaysia.

John, A., \& Walle, V. D. (2001). Elementary and middle school mathematics (4 ed.). New York: Addison Wesley.

Kennedy, L. M., \& Tipps, S. (2000). Guiding children's learning of Mathematics (Vol. 9). Belmont, CA:

Wadsworth. 
Labinowicz, E. (1985). Learning from children: New beginning for teaching numerical thinking. Menlo Park, CA: AWL Supplemental.

Lithner, J. (2008). A research framework for creative and imitative reasoning. Educational Studies in Mathematics, $67(3), 255-276$.

Lithner, J. (2015). Learning mathematics by creative or imitative reasoning. In Selected Regular Lectures from the 12th International Congress on Mathematical Education (pp. 487-506). Springer International Publishing.

Lipman, M. (2003). Thinking in education (2nd ed.). Cambridge, UK: Cambridge UP.

Lovitt, C., \& Clarke, D. (1992). The Mathematics curriculum and teaching program: Professional development package - Activity Bank Volume I. Victoria, Australia: Curriculum Corporation.

Magno, C. (2011). The use of study strategies on Mathematical problem solving. International Journal, 6(2).

Malaysian Ministry of Education. (2001). Kemahiran berfikir dalam pengajaran pembelajaran [Thinking skills in teaching and learning]. Kuala Lumpur: Curriculum Development Centre.

Ministry of Education Malaysia. Putrajaya Malaysia: Kementerian Pendidikan Malaysia. (2013). Malaysia education blueprint 2013-2025 (preschool to post-secondary education) Retrieved from http://www.moe.gov.my/en/pelanpembangunan-pendidikan-malaysia-2013-2025.

National Council of Teachers of Mathematics [NCTM]. (1989). Curriculum and evaluation standards for Mathematics. Reston, VA: Author.

National Council of Teachers of Mathematics [NCTM]. (2000). Principles and standards for school mathematics. Reston, VA: Author.

Noor Shah \& Sazelli, A.G. (2010). Teaching mathematics in secondary schools: theories and practices. UPSI: Ampang Press Sdn. Bhd.

Noraini, I. (2006). Teaching and learning of mathematics: Making sense and development of cognitive abilities'. Utusan Publications \& Distributors.

Reys, B. J., \& Long, V. M. (1994). Teachers as architect of mathematical tasks. Teaching Children Mathematics, 1 (January 1995), pp. 296-299.

Reys, R. E., Lindquist, M. M., Lambdin, D. V., Smith, N. L., \& Suydam, M. N. (2001). Helping children learn mathematics (6 ed.). New York: Wiley.

Rittle-Johnson, B., \& Schneider, M. (2014). Developing conceptual and procedural knowledge of mathematics. Oxford handbook of numerical cognition. Oxford, UK: Oxford University Press. doi, 10.

Schank, R. C. (2004). Making minds less well educated than our own. Mahwah, NJ: Erlbaum.

Sonnabend, T. (1997). Mathematics for elementary teachers: An interactice approach (2nd ed.). Belmont, CA: Brooks/ Cole.

Troutman, A. P., \& Lichtenberg, B. K. (2003). Mathematics a good beginning (6 ed.). Belmont, CA: Wadsworth.

Turner, J. C., Warzon, K. B., \& Christensen, A. (2011). Motivating Mathematics Learning Changes in Teachers' Practices and Beliefs During a Nine-Month Collaboration. American Educational Research Journal, 48(3), 718-762.

Yang, E. F., Chang, B., Cheng, H. N., \& Chan, T. W. (2016). Improving Pupils' Mathematical Communication Abilities through Computer-Supported Reciprocal Peer Tutoring. Journal of Educational Technology \& Society, 19(3), 

